\title{
The relationship between the degree of organization's virtualization and the organizational ability
}

\author{
Hassan Rezazadeh ${ }^{a^{*}}$ and Hamed Molaei ${ }^{\mathrm{b}}$
}

${ }^{a}$ Department of Industrial Engineering, University of Tabriz, Tabriz, Iran

${ }^{b}$ School of Science, Engineering \& Technology, Istanbul Technical University, Turkey

CH R O N I CLE A B S T RA C T

Article history:

Received: November 26, 2017

Received in revised format: January 31,2018

Accepted: April 19, 2018

Available online:

April 19, 2018

Keywords:

Human Resources

Virtual Organizations

Organizational Ability

\begin{abstract}
The term virtual organization is used to describe the organizations that are united with other organizations to benefit from the relative advantages of other organizations. These organizations are established based on different patterns to use information technology for building quick, cheap, and easy communications. Virtual organizations use effective and useful strategies to keep up with the rapid and fundamental changes in the new world. Information Technology (IT) is a facilitator that has made it possible to create virtual organizations. In these organizations, indicators such as the level of collaboration with partners, the rate of the implementation of IT and other issues such as how to work together based on mutual trust, how to choose partners and how to resolve disputes with partners are used to form the virtual teams to help determine the viability of the organizations. The virtual organization, as a fact, is the result of technological advancements and creativity in organizing firms to face with the turbulent environment and features of the post-industrial age. In today's world of business, virtual organizations are trying to benefit from knowledge-based employees, who have high flexibility and significant efficiency to respond to the needs of a turbulent market and to create significant competitive advantage. In order to benefit from such organizations, their managerial issues should be identified and organized in a good manner. This study examines the relationship between the degree of organization's virtualization and the organizational ability (employees). The study designs a questionnaire and distributes it among some experts and, using Pearson correlation test, examines the hypotheses of the survey. The results indicate that there was a significant difference between the degree of virtualization of organization and organizational ability.
\end{abstract}

\section{Introduction}

Virtual organization is considered as an organizing strategy used for a new workplace and when it is developed, it aims to optimize the use of information technology in creating competitive advantage and benefiting knowledge-based employees in group activities (Larsen \& McInerney, 2002; Tu et al., 2002). The virtual organization is considered as the practical application of information technology, which has been mentioned as future organizations because of reasons such as creating new markets and products and the flexibility to respond to market needs (Pletsch, 1998). The virtual organizations management has 5 specialized fields (Fritz \& Manheim, 1998; Rowden, 2000):

\footnotetext{
* Corresponding author.

E-mail address: hrezazadeh@tabrizu.ac.ir (H. Rezazadeh) 

A. Human Resource Management
B. Communication management
C. Process management
D. Knowledge management
E. Technology Management

Virtual organizations may have some differences with former bureaucratic organizations, but Peter Durker's view ${ }^{1}$ holds for these organizations. The success of organizational cooperation is more associated with some human factors, which depends on technology (Vakola \& Wilson, 2004). Although virtual organizations are developed quickly, but little research has been carried out in the field of human resources and the behavioral characteristics of employees in such organizations (Raghuram et al. 2001). Issues such as performance, job satisfaction, organizational identity, organizational commitment, and job quit rates are significant and challenging topics in the field of human resource management for most virtual organizations (Shin, 2004; Tseng, 2008). The employees' commitment towards virtualization is one of the important factors influencing on the productivity of such organizations. Therefore, there is a need to study the organizational commitment and this study investigates the relationship between the degree of virtualization of an organization and organizational commitment.

\section{Literature review}

\subsection{Virtual organization}

Virtual organization was first introduced by Byrne (1993). According to Upton and McAfee (1996), the virtual organization is defined as "a collection of companies, each of which focuses on its expertise and can work flexibly with each other, with the help of electronic networks irrespective of their location". The most important reasons for the creation of virtual organizations are:

A. Maximizing flexibility versus environmental changes,

B. Focusing on competitive advantage,

C) Resizing organization according to market changes,

D) Development of the organization supply chain (Martinez et al., 2001; Sinclair et al., 2005).

According to Jägers et al. (1998), the general characteristics of virtual organizations are:
A. Lacks any boundaries
B. Completing each other's competitive advantages / resource sharing
C. Knowledge sharing
D. Geographical distribution
E. Changing partners
F. The same participation
G. Instantaneous electronic communications.

Also, collaboration in the electronic platform (Han et al., 2007), temporary resource sharing for common objectives (Kerschbaum \& Robinson, 2009), and accurate and fast response to customer needs, geographic dispersion is another common perspective of virtual organizations. The life cycle of the virtual organization includes four stages: the establishment, work operations, gradual evolution and transformation and liquidation ( $\mathrm{Lin} \& \mathrm{Lu}, 2005$ ). In fact, the virtual organization forms in order to take advantage of business opportunities, and when this opportunity ends, the virtual organization will also be eliminated (IP et al., 2003). According to Bauer and Köszegi (2003) there are seven dimensions in four main fields for the virtual organization:

\footnotetext{
${ }^{1}$ In this perspective, human factor is considered as the most important capital of the organization.
} 
A-Differentiation, modularity and heterogeneity of companies: A virtual organization requires several features in order to meet customers' complex and unique requirements. For this purpose, each member of the firms with the virtual organization must have special features and benefits considered as competitive advantage. The dimensions of this field include creation of the value in a virtual way and focus on competitive advantages.

B- Configuration, a temporary and variable network: The customers believe that a virtual organization, with a single entity, is a set of independent companies that come together when an opportunity is created. In these situations, subsystems are constantly changing due to market characteristics and customer needs, but there is no change in the nature of the virtual organization. The dimensions of this field are: 1. The general characteristics of the virtual network, 2. The independence of the partner companies, 3 . The formalization and formal obligations between the partner companies (Bauer \& Köszegi, 2003).

C- Integration, trust and coordination mechanism: Virtual organizations need mechanisms for coordination and integration due to the distinction between companies in a virtual organization and their interaction with each other in a temporary manner. The most important coordinating factor in this field is the mutual trust between partners. In the control mechanism by trust, behavior is driven by norms, shared values, and self-control. Trust as a coordination mechanism is the only dimension of this field (Bauer \& Köszegi, 2003).

D-Technology: ICT is considered as a platform for coordinating activities and value chains in a virtual organization. The dimensions of this field are: 1. Use of Information and Communication Technology (Bauer \& Köszegi, 2003).

A virtual organization, according to the characteristics described in this study, can be defined as "A flexible and temporary network of independent organizations that share their competitive advantages in order to benefit from a business opportunity by optimizing the value chain of the organization's processes" (Bauer \& Köszegi, 2003). The degree of organization's virtualization is associated with the degree to which the organization possesses each of these characteristics. In this study, according to four characteristics proposed for virtual organizations, in order to assess the degree of virtualization of the organization, eight indicators are used including virtual value chain, competitive advantage, network characteristics, degree of formality, integrity, trust, fairness and information and communication systems.

\subsection{Human Resource Management}

Human resource management is defined as management of fields related to the human resources of the organization (Attracting, Staffing, Development and Maintenance) (Boxall et al., 2007). Human resource management has attracted the experts' attention as a tool of organizational goals, plans and organizational strategies (Dyer \& Nobeoka, 2000). Human resource management has dimensions of attracting, staffing, development and maintenance of human resources, which are described as follows:

A) Human Resource management in the field of attracting human resources: The aim of human resource planning is to determine micro and macro strategies for the supply and demand of human resources, the information system for human resources and the supply of human resources (Delery \& Roumpi, 2017)

B) Human resource management in the field of human resources staffing: it is associated with completion of human resources management positions. In this stage, the basic characteristics of the job, the job description, the conditions for obtaining a job, must be detected; which means, the characteristics, which are the main infrastructure of the job and without them, a particular candidate cannot do the job in a satisfactory manner must be determined (Meyer et al., 2004) to be on the path to career progress. Other activities include: supervising the recruitment process, 
analysis of jobs, selection and recruitment of deserving people, determining the correct organizational position, the relationship of that job with other businesses, the knowledge and skills necessary for doing that.

C) Human resource management in the field of human resource development: It is associated with education to improve human resources quality, which is an increase in learning opportunities. Improvement of people's development to improve individual and organizational effectiveness appears in this field. Other development activities include: the process of socializing, educating the manager, and training the skills needed (Kesti, 2012).

D) Human resource management in the field of human resource maintenance: Performance management, salary and benefit package. Other maintenance activities include designing a performance appraisal system, designing a reward system, designing a payroll system, mediating between organizations and syndicates, designing a system of suggestions and complaints, designing a work safety and health system, and designing a disciplinary system (Alker \& McHugh, 2000).

\subsection{Accrual challenge in virtual organization}

In 2004, Shin during an extensive research examined the degree of virtualization of the organization and its relationship with the organization's human resources management. In this study, the degree of virtualization of the organization was determined by measuring the dimensions of the virtual organization (employee location, temporality, culture and geographical dispersion). Then, its relationship with suitability factors in association with person and job (person and organization fit, person and work group fit, person and job characteristics fit) were measured. Finally, the effect of this relationship on job performance, job satisfaction, organizational commitment and job quit rate has been evaluated. The results of this study show that, there was a significant relationship between the degree of organization's virtualization and the person and job fit. Considering the positive relationship between person and job fit with job performance, job satisfaction and organizational commitment and its inverse relationship with job quit rates, it can be concluded that the degree of organization's virtualization has a significant impact on the mentioned issues (Shin, 2004).

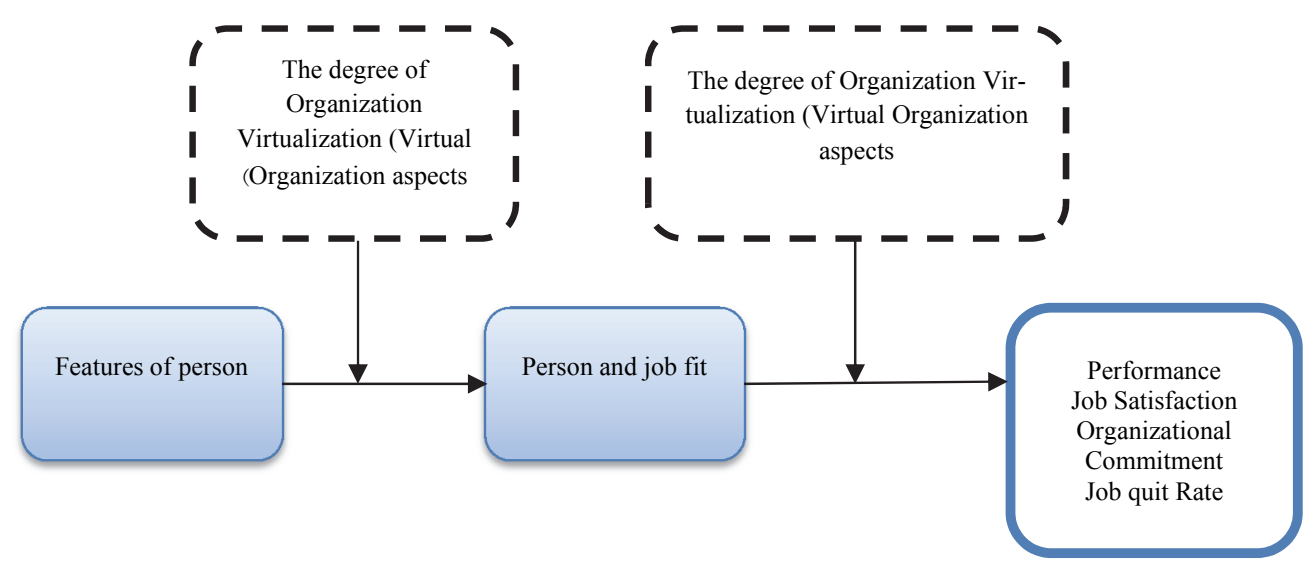

Fig. 1. A model of employee and job fit in the virtual organization (Shin, 2004)

Haslam (2001), Meyer et al. (1993, 2004, 2006), Van Knippenberg and Sleebos (2006), and Gagné and Deci (2005) reported a close relationship between organizational identity and organizational commitment, and the effect of the organizational identity reduction on organizational commitment. It is clear that the challenge of organizational identity in virtual organizations creates a crisis of organizational commitment, therefore we are facing with a negative relationship between organizational commitment 
and job quit rates of the knowledge-based professionals (Akroyd et al., 2009; Gandhi et al., 2018). Job quit, in addition to reducing the productivity of the organization will lead to recruitment costs, training, reduced collective morale and corporate organizational memory erosion (Abbott et al., 2005). The relationship between the degree of organization virtualization and organizational commitment with its consequences is shown in the following figure.

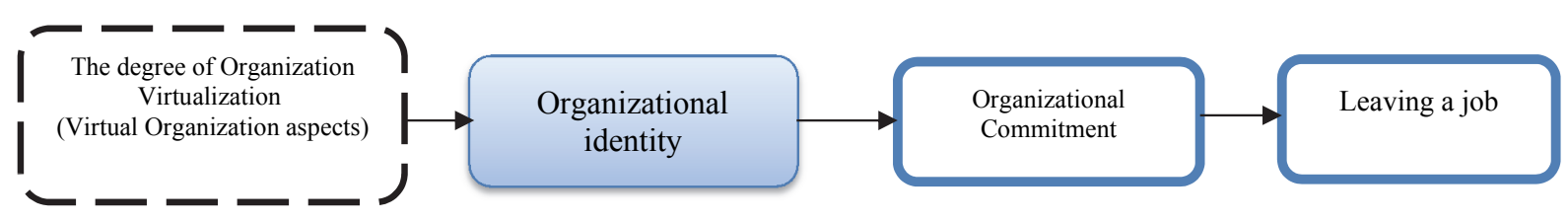

Fig. 2. Relationship between the degree of virtualization of the organization and the organizational identity

Most researchers believe that organizational commitment makes the person dependent on the organization and reduces the probability of leaving a job (Gandhi et al., 2006). The manpower of the virtual organization includes IT experts, which is the most valuable strategic source of virtual organization. According to Tseng (2008), IT experts have the highest job quit rates. The main reasons for this phenomenon include rapid technological changes, high job stress, better job opportunities, and more. Ellison (1999) during a study examined the effect of new technologies on remote employees and virtual teams, and concluded that remote work could reduce employees' commitment to their jobs, and this is due to working in an environment that is ambiguous, isolated and lacking external support structure (Ellison, 1999). Of course, we should mentioned that low commitment in remote work has not always been approved by the researchers. A team of researchers say that the e-work environment could improve the feelings of freedom and flexibility of employees, which leads to the development of relationships with virtual colleagues and increasing commitment. Workman et al. (2003) used the cognitive style mediating variable to examine the effect of remote work on employees' commitment and claimed that since employees with an internal cognitive style, and with global cognitive style are more interested in solitary work, they will have more commitment than employees with external cognitive style, and local cognitive style.

\section{The proposed study}

In this study, The Kolmogorov-Smirnov test was used to check the normal distribution of the data of the variables in order to identify the applicable tests, and because of the normal distribution of the data, the Pearson's parametric test was used to examine the hypotheses. Table 1 shows the results of this test.

\section{Table 1}

Results of Kolmogorov-Smirnov in the examination of the normal distribution of the data of each of the variables of research

\begin{tabular}{lcccc}
\hline & The statistics & Degrees of freedom & Significance level & Distribute data \\
\hline Ability & 0.152 & 110 & 0.161 & Distribution is normal \\
Clarity & 0.139 & 110 & 0.200 & Distribution is normal \\
Help & 0.135 & 110 & 0.200 & Distribution is normal \\
Encouragement & 0.150 & 110 & 0.163 & Distribution is normal \\
Organizational assessment & 0.137 & 110 & 0.200 & Distribution is normal \\
Organizational Credit & 0.146 & 110 & 0.181 & Distribution is normal \\
Physical requirements & 0.139 & 110 & 0.200 & Distribution is normal \\
Organizational Performance & 0.169 & 110 & 0.098 & Distribution is normal \\
Organization degree & 0.142 & 110 & 0.189 & Distribution is normal \\
\hline
\end{tabular}

According to the results of Kolmogorov-Smirnov, the distribution of research variables is normal. Accordingly, we can use parametric tests as suitable tests to examine the hypotheses of this study. The one sample t-test was used to measure the status of each of the variables and a simple regression was 
used to explain the relationship between the degree of virtualization of the organization and organizational performance.

\subsection{The main hypothesis}

Pearson correlation test was used to examine the relationship between the degree of organization's Virtualization and organizational performance, which is the main hypothesis of this survey as follows,

Null hypothesis: There is no significant relationship between the degree of virtualization of an organization and organizational performance.

Research hypothesis: There is a significant relationship between the degree of virtualization of the organization and organizational performance.

The results of this test are presented in Table 2 as follows,

\section{Table 2}

The results of testing the relationship between the degree of virtualization and organizational performance

\begin{tabular}{lccc}
\hline Variables & The correlation coefficient & Significance level & Conclusion \\
\hline $\begin{array}{c}\text { The degree of virtualization and } \\
\text { organizational performance }\end{array}$ & 0.557 & 0.001 & Approved \\
\hline
\end{tabular}

According to the results of Pearson correlation test, given than the significance level obtained (0.001) is smaller than 0.05 , the relationship between the degree of virtualization and organizational performance is significant. Also, the negative correlation coefficient indicates there is a negative relationship between the two variables, meaning that, in a two-way relationship, the organizational performance decreases by increasing the degree of virtualization of an organization. Therefore, the null hypothesis is rejected and the hypothesis of the research is confirmed.

\subsubsection{The first hypothesis}

Pearson correlation test was used to examine the relationship between the degree of organization's Virtualization and organizational ability. The results of this test are presented in the Table 3 .

Null hypothesis: There is no significant relationship between the degree of virtualization of an organization and organizational ability.

Research hypothesis: There is a significant relationship between the degree of virtualization of the organization and organizational ability.

Table 3

The relationship between virtualization and organizational ability

\begin{tabular}{cccc}
\hline Variables & The correlation coefficient & Significance level & Conclusion \\
\hline $\begin{array}{c}\text { The degree of virtualization } \\
\text { and organizational ability }\end{array}$ & -0.371 & 0.001 & The relationship is significant \\
\hline
\end{tabular}

According to the results of Pearson correlation test, given than the significance level obtained (0.001) is smaller than 0.05 , the relationship between the degree of virtualization and organizational ability is significant. Also, the negative correlation coefficient indicates there is a negative relationship between the two variables, meaning that, in a two-way relationship, organizational ability decreases by increasing the degree of virtualization of an organization. Therefore, the null hypothesis is rejected and the hypothesis of the research is confirmed.

\subsubsection{The second hypothesis}

Pearson correlation test was used to examine the relationship between the degree of organization's Virtualization and Clarity. The results of this test are presented in Table 4. 
Null hypothesis: There is no significant relationship between the degree of virtualization of an organization and Clarity.

Research hypothesis: There is a significant relationship between the degree of virtualization of the organization and Clarity.

\section{Table 4}

The results of the testing the relationship between the degree of virtualization of the organization and clarity

\begin{tabular}{cccc}
\hline Variables & The correlation coefficient & Significance level & Conclusion \\
\hline $\begin{array}{c}\text { The degree of virtualization and } \\
\text { clarity }\end{array}$ & -0.441 & 0.001 & $\begin{array}{c}\text { The relationship is } \\
\text { significant }\end{array}$ \\
\hline
\end{tabular}

According to the results of Pearson correlation test, given than the significance level obtained (0.001) is smaller than 0.05 , the relationship between the degree of virtualization and Clarity is significant. Also, the negative correlation coefficient indicates there is a negative relationship between the two variables, meaning that, in a two-way relationship, Clarity decreases by increasing the degree of virtualization of an organization. Therefore, the null hypothesis is rejected and the hypothesis of the research is confirmed.

\subsubsection{The third hypothesis}

Pearson correlation test was used to examine the relationship between the degree of organization's Virtualization and Help. The results of this test are presented in Table 5 as follows,

Null hypothesis: There is no significant relationship between the degree of virtualization of an organization and Help.

Research hypothesis: There is a significant relationship between the degree of virtualization of the organization and Help.

\section{Table 5}

The results of testing the relationship between the degree of virtualization of the organization and Help

\begin{tabular}{cccc}
\hline Variables & The correlation coefficient & Significance level & Conclusion \\
\hline $\begin{array}{c}\text { The degree of virtualization and } \\
\text { Help }\end{array}$ & -0.520 & 0.001 & The relationship is significant \\
\hline
\end{tabular}

According to the results of Pearson correlation test, given than the significance level obtained (0.001) is smaller than 0.05 , the relationship between the degree of virtualization and Help is significant. Also, the negative correlation coefficient indicates there is a negative relationship between the two variables, meaning that, in a two-way relationship, Help decreases by increasing the degree of virtualization of an organization. Therefore, the null hypothesis is rejected and the hypothesis of the research is confirmed.

\subsubsection{The fourth hypothesis}

Pearson correlation test was used to examine the relationship between the degree of organization's Virtualization and Encouragement. The results of this test are presented in Table 6.

Null hypothesis: There is no significant relationship between the degree of virtualization of an organization and Encouragement.

Research hypothesis: There is a significant relationship between the degree of virtualization of the organization and Encouragement.

\section{Table 6}

The results of testing the relationship between the degree of virtualization and Encouragement

\begin{tabular}{cccc}
\hline Variables & The correlation coefficient & Significance level & Conclusion \\
\hline $\begin{array}{c}\text { The degree of virtualization and } \\
\text { Encouragement }\end{array}$ & -0.520 & 0.001 & $\begin{array}{c}\text { The relationship is } \\
\text { significant }\end{array}$ \\
\hline
\end{tabular}


According to the results of Pearson correlation test, given than the significance level obtained (0.001) is smaller than 0.05, the relationship between the degree of virtualization and Encouragement is significant. Also, the negative correlation coefficient indicates there is a negative relationship between the two variables, meaning that, in a two-way relationship, Encouragement decreases by increasing the degree of virtualization of an organization. Therefore, the null hypothesis is rejected and the hypothesis of the research is confirmed.

\subsubsection{The fifth hypothesis}

Pearson correlation test was used to examine the relationship between the degree of organization's Virtualization and Organizational assessment. The results of this test are presented in Table 7.

Null hypothesis: There is no significant relationship between the degree of virtualization of an organization and Organizational assessment.

Research hypothesis: There is a significant relationship between the degree of virtualization of the organization and Organizational assessment.

Table 7

The results of testing the relationship between the degree of virtualization and organizational assessment

\begin{tabular}{cccc}
\hline Variables & $\begin{array}{c}\text { The correlation } \\
\text { coefficient }\end{array}$ & Significance level & Conclusion \\
\hline $\begin{array}{c}\text { The degree of virtualization and } \\
\text { Organizational assessment }\end{array}$ & -0.424 & 0.001 & $\begin{array}{c}\text { The relationship is } \\
\text { significant }\end{array}$ \\
\hline
\end{tabular}

According to the results of Pearson correlation test, given than the significance level obtained (0.001) is smaller than 0.05 , the relationship between the degree of virtualization and organizational assessment is significant. Also, the negative correlation coefficient indicates there is a negative relationship between the two variables, meaning that, in a two-way relationship, Organizational assessment decreases by increasing the degree of virtualization of an organization. Therefore, the null hypothesis is rejected and the hypothesis of the research is confirmed.

\subsubsection{The sixth hypothesis}

Pearson correlation test was used to examine the relationship between the degree of organization's Virtualization and Organizational Credit. The results of this test are presented in Table 8.

Null hypothesis: There is no significant relationship between the degree of virtualization of an organization and Organizational Credit.

Research hypothesis: There is a significant relationship between the degree of virtualization of the organization and Organizational Credit.

\section{Table 8}

The results of testing the relationship between the degree of virtualization and organizational credit

\begin{tabular}{cccc}
\hline Variables & The correlation coefficient & Significance level & Conclusion \\
\hline $\begin{array}{c}\text { The degree of virtualization and } \\
\text { Organizational Credit }\end{array}$ & -0.466 & 0.001 & $\begin{array}{c}\text { The relationship is } \\
\text { significant }\end{array}$ \\
\hline
\end{tabular}

According to the results of Pearson correlation test, given than the significance level obtained (0.001) is smaller than 0.05 , the relationship between the degree of virtualization and Organizational Credit is significant. Also, the negative correlation coefficient indicates there is a negative relationship between the two variables, meaning that, in a two-way relationship, Organizational Credit decreases by increasing the degree of virtualization of an organization. Therefore, the null hypothesis is rejected and the hypothesis of the research is confirmed. 


\subsubsection{The seventh hypothesis}

Pearson correlation test was used to examine the relationship between the degree of organization's Virtualization and Physical requirements. The results of this test are presented in Table 9 as follows,

Null hypothesis: There is no significant relationship between the degree of virtualization of an organization and Physical requirements.

Research hypothesis: There is a significant relationship between the degree of virtualization of the organization and Physical requirements.

\section{Table 9}

The results of testing the relationship between the degree of virtualization and physical requirements

\begin{tabular}{cccc}
\hline Variables & $\begin{array}{c}\text { The correlation } \\
\text { coefficient }\end{array}$ & Significance level & Conclusion \\
\hline $\begin{array}{c}\text { The degree of virtualization and Physi- } \\
\text { cal requirements }\end{array}$ & -0.466 & 0.001 & $\begin{array}{c}\text { The relationship is } \\
\text { significant }\end{array}$ \\
\hline
\end{tabular}

According to the results of Pearson correlation test, given than the significance level obtained (0.001) is smaller than 0.05 , the relationship between the degree of virtualization and Physical requirements is significant. Also, the negative correlation coefficient indicates there is a negative relationship between the two variables, meaning that, in a two-way relationship, Physical requirements decreases by increasing the degree of virtualization of an organization. Therefore, the null hypothesis is rejected and the hypothesis of the research is confirmed.

\subsection{The results of the communication study using regression test}

The regression test is used to evaluate the effect of virtualization on each aspect of organizational performance separately and in order to investigate the effect of degree of virtualization on the organizational performance variable. The results of this test are presented in Table 10 as follows.

\section{Table 10}

Results of regression analysis coefficients of each of the variables in the model in the fit of dependent variable

\begin{tabular}{|c|c|c|c|c|c|c|c|}
\hline & & \multicolumn{2}{|c|}{$\begin{array}{c}\text { Non-standard } \\
\text { coefficients }\end{array}$} & \multirow{2}{*}{$\begin{array}{c}\begin{array}{c}\text { Standard } \\
\text { coefficients }\end{array} \\
\beta\end{array}$} & \multirow{2}{*}{$\mathrm{t}$} & \multirow{2}{*}{$\begin{array}{c}\text { Significance } \\
\text { level }\end{array}$} & \multirow{2}{*}{$\begin{array}{l}\text { Significance } \\
\text { of the effect }\end{array}$} \\
\hline & & $\mathrm{B}$ & $\begin{array}{l}\text { standard } \\
\text { error }\end{array}$ & & & & \\
\hline \multirow{8}{*}{$\begin{array}{c}\text { Degree of } \\
\text { Organization } \\
\text { virtualization }\end{array}$} & Ability & -0.502 & 0.121 & -0.371 & -4.151 & 0.001 & Significant \\
\hline & Clarity & -0.515 & 0.101 & -0.441 & -5.109 & 0.001 & Significant \\
\hline & Help & -0.587 & 0.093 & -0.520 & -6.322 & 0.001 & Significant \\
\hline & Encouragement & -0.514 & 0.108 & -0.417 & -4.744 & 0.001 & Significant \\
\hline & $\begin{array}{l}\text { Organizational } \\
\text { assessment }\end{array}$ & -0.446 & 0.092 & -0.424 & -4.872 & 0.001 & Significant \\
\hline & $\begin{array}{l}\text { Organizational } \\
\text { Credit }\end{array}$ & -0.547 & 0.100 & -0.466 & -4.473 & 0.001 & Significant \\
\hline & $\begin{array}{l}\text { Physical } \\
\text { requirements }\end{array}$ & -0.622 & 0.066 & -0.675 & -9.501 & 0.001 & Significant \\
\hline & $\begin{array}{l}\text { Organizational } \\
\text { Performance }\end{array}$ & -0.750 & 0.108 & -0.557 & -6.973 & 0.001 & Significant \\
\hline
\end{tabular}

The significance levels obtained are less than 0.05 , therefore the degree of virtualization of the organization has a significant effect on organizational performance as well as its dimensions at the $95 \%$ confidence level.

\subsection{The status of research variables}

Finally, we test the difference between the mean of the variables where the hypothesis is stated as follows, 
Null hypothesis: There is no significant difference between the mean of each of the research variables and the average level.

Research hypothesis: There is significant difference between the mean of each of the research variables and the average level.

\section{Table 11}

Statistical Indices of central tendency and dispersion of each of the research variables

\begin{tabular}{lcccc}
\hline & Number & Average & The standard deviation & Standard error of the mean \\
\hline Ability & 110 & 2.66852 & 0.8461 & 0.08034 \\
Clarity & 110 & 2.4727 & 0.72658 & 0.069228 \\
Help & 110 & 2.5659 & 0.70359 & 0.06708 \\
Encouragement & 110 & 2.6500 & 0.76716 & 0.07315 \\
Organizational assessment & 110 & 2.4705 & 0.65467 & 0.06242 \\
Organizational Credit & 110 & 2.6341 & 0.73078 & 0.06968 \\
Physical requirements & 110 & 2.6019 & 0.57422 & 0.05475 \\
Organizational Performance & 110 & 2.5886 & 0.83816 & 0.07992 \\
Organization virtualization degree & 110 & 2.5833 & 0.62248 & 0.05935 \\
\hline
\end{tabular}

A single-sample $t$ test is used to compare the mean of each of the variables with an average level. This test compares the average of the data of a variable with a given value and indicates the significance or lack of significance of their differences. The results of a single-sample t-test are presented in Table 12.

\section{Table 12}

Single-sample $t$ test results $t$ in comparison of the average of each of the research variables and the average level

\begin{tabular}{lcccccc}
\hline & \multicolumn{4}{c}{ Test value =3 } \\
\cline { 2 - 7 } & $\mathrm{t}$ & $\begin{array}{c}\text { Degrees of } \\
\text { freedom }\end{array}$ & $\begin{array}{c}\text { Significance } \\
\text { level }\end{array}$ & $\begin{array}{c}\text { Average } \\
\text { difference }\end{array}$ & $\begin{array}{c}\text { Confidence level 95 \% } \\
\text { lower limit } \\
\text { upper limit }\end{array}$ \\
\hline Ability & -4.130 & 109 & 0.001 & -0.33182 & -0.491 & -0.1726 \\
Clarity & -7.611 & 109 & 0.001 & -527227 & -0.6646 & -0.3900 \\
Help & -6.471 & 109 & 0.001 & -0.43409 & -0.5671 & -0.3011 \\
Encouragement & -4.785 & 109 & 0.001 & -0.3500 & $-0 . .495$ & -0.2050 \\
Organizational assessment & -4.785 & 109 & 0.001 & -0.52955 & -0.65333 & -0.4058 \\
Organizational Credit & -5.252 & 109 & 0.001 & -0.36591 & -0.5040 & -0.2278 \\
Physical requirements & -7.270 & 109 & 0.001 & -0.39805 & -0.5066 & -0.2895 \\
Organizational Performance & -5.148 & 109 & 0.001 & -0.41136 & -0.5698 & -0.2530 \\
Organization virtualization degree & -7.020 & 109 & 0.001 & -0.41667 & -0.5343 & -0.2990 \\
\hline
\end{tabular}

According to the results of single-sample t-test, there is a significant difference between the mean of each of the research variables and the average value (3). In other words, based on the absolute value of $t$ values calculated, the $t$ reference value for the degree of freedom 109 (1.982) and the absolute value of $t$ values calculated, which have the greater value, also based on the calculated levels of significance $(0.001)$ and given that its value is smaller than 0.05 , it can be concluded that at $95 \%$ confidence level there is a significant difference between the mean of each of the variables and the mean value (3). Therefore, the null hypothesis is based on the lack of significance of difference between the mean of each of the research variables and the average level (3) and the hypothesis of the research is confirmed.

\section{Conclusions}

Significant changes in the workplace, the variety and specialization of tasks, organizational boundaries, employee dispersion, and, in short, the virtualization of organizations will be associated with a new challenge for managers and employees. The importance of the commitment issue is highlighted by working in environments where employees work away from each other and managers. Reducing productivity of organization, cost of staffing and disrupting organizational processes, as well as weakening the morale of other employees are some disadvantages of low organizational commitment. This study was carried out aimed to examine the new challenge of human resource management in the field of organizational ability in relation to virtual organizations. In this regard, the effect of the degree of 
virtualization of the organization on the organizational ability has been investigated. According to the results of this study, there is a significant relationship between the degree of virtualization of the organization and organizational ability. The result can be justified by the challenges faced by virtual organizations, such as reducing interpersonal and face-to-face communications, increasing ambiguity and job stress, and existence of more attractive job opportunities. This result is similar to the results obtained by Ellison (Ellison, 1999). This relationship can also be attributed to the existence of more job opportunities in the external environment. IT also provides this opportunity for employees to easily shift into another job and reduces the fear due to the cost of leaving a job in the employees.

\section{References}

Abbott, G. N., White, F. A., \& Charles, M. A. (2005). Linking values and organizational commitment: A correlational and experimental investigation in two organizations. Journal of Occupational and Organizational Psychology, 78(4), 531-551.

Akroyd, D., Legg, J., Jackowski, M. B., \& Adams, R. D. (2009). The impact of selected organizational variables and managerial leadership on radiation therapists' organizational commitment. Radiography, 15(2), 113-120.

Alker, L., \& McHugh, D. (2000). Human resource maintenance?-Organisational rationales for the introduction of employee assistance programmes. Journal of Managerial Psychology, 15(4), 303-323.

Bauer, R., \& Köszegi, S. T. (2003). Measuring the degree of virtualization. Electronic Journal of Organizational Virtualness, 5(2), 26-46.

Boxall, P., Purcell, J., \& Wright, P. (2007). Human resource management: scope, analysis, and significance. Oxford Handbook of Human Resource Management.

Byrne, J. A. (1993). The virtual corporation. International Business, 2(8), 37-41.

Cichy, R. F., Cha, J., \& Kim, S. (2009). The relationship between organizational commitment and contextual performance among private club leaders. International Journal of Hospitality Management, 28(1), 53-62.

Delery, J. E., \& Roumpi, D. (2017). Strategic human resource management, human capital and competitive advantage: is the field going in circles?. Human Resource Management Journal, 27(1), 121.

Dyer, J. H., \& Nobeoka, K. (2000). Creating and managing a high-performance knowledge-sharing network: the Toyota case. Strategic Management Journal, 21(3), 345-367.

Ellison, N. B. (1999). Social impacts: New perspectives on telework. Social Science Computer Review, 17(3), 338-356.

Fritz, M. B., \& Manheim, M. L. (1998). Managing virtual work: a framework for managerial action. Organizational Virtualness, 123.

Gagné, M., \& Deci, E. L. (2005). Self-determination theory and work motivation. Journal of Organizational Behavior, 26(4), 331-362.

Gandhi, S., Sachdeva, A \& Gupta, A. (2018). Developing a scale to measure employee service quality in Indian SMEs. Management Science Letters, 8(5), 455-474.

Güleryüz, G., Güney, S., Aydın, E. M., \& Aşan, Ö. (2008). The mediating effect of job satisfaction between emotional intelligence and organisational commitment of nurses: A questionnaire survey. International Journal of Nursing Studies, 45(11), 1625-1635.

Han, S. H., Chin, K. H., \& Chae, M. J. (2007). Evaluation of CITIS as a collaborative virtual organization for construction project management. Automation in Construction, 16(2), 199-211.

Haslam, S.A. (2001). Psychology in Organization (The Social Identity Approach). SAGE Publication, London.

Ip, W. H., Huang, M., Yung, K. L., \& Wang, D. (2003). Genetic algorithm solution for a risk-based partner selection problem in a virtual enterprise. Computers \& Operations Research, 30(2), $213-$ 231. 
Jägers, H., Jansen, W., \& Steenbakkers, W. (1998). Characteristics of virtual organizations. Organizational virtualness, 65-77.

Kerschbaum, F., \& Robinson, P. (2009). Security architecture for virtual organizations of business web services. Journal of Systems Architecture, 55(4), 224-232.

Kesti, M. (2012). The tacit signal method in human competence based organization performance development $. \mathrm{fi}=$ Lapin yliopistokustannus $\mid$ en $=$ Lapland University Press $\mid$.

Van Knippenberg, D., \& Sleebos, E. (2006). Organizational identification versus organizational commitment: self-definition, social exchange, and job attitudes. Journal of Organizational Behavior, 27(5), 571-584.

Larsen, K. R., \& McInerney, C. R. (2002). Preparing to work in the virtual organization. Information \& Management, 39(6), 445-456.

Lin, L. H., \& Lu, I. Y. (2005). Adoption of virtual organization by Taiwanese electronics firms: An empirical study of organization structure innovation. Journal of Organizational Change Management, 18(2), 184-200.

Martinez, M. T., Fouletier, P., Park, K. H., \& Favrel, J. (2001). Virtual enterprise-organisation, evolution and control. International Journal of Production Economics, 74(1-3), 225-238.

Meyer, J. P., Allen, N. J., \& Smith, C. A. (1993). Commitment to organizations and occupations: Extension and test of a three-component conceptualization. Journal of Applied Psychology, 78(4), 538.

Meyer, J. P., Becker, T. E., \& Vandenberghe, C. (2004). Employee commitment and motivation: a conceptual analysis and integrative model. Journal of Applied Psychology, 89(6), 991.

Meyer, J. P., Becker, T. E., \& Van Dick, R. (2006). Social identities and commitments at work: Toward an integrative model. Journal of Organizational Behavior, 27(5), 665-683.

O’Neill, J. W., Harrison, M. M., Cleveland, J., Almeida, D., Stawski, R., \& Crouter, A. C. (2009). Work-family climate, organizational commitment, and turnover: Multilevel contagion effects of leaders. Journal of Vocational Behavior, 74(1), 18-29.

Pletsch, A. (1998). Organizational Virtualness in Business and Legal Reality. Organizational Virtualness: Proceedings of the VoNet Workshop, April 1998.

Raghuram, S., Garud, R., Wiesenfeld, B., \& Gupta, V. (2001). Factors contributing to virtual work adjustment. Journal of Management, 27(3), 383-405.

Rowden, R. W. (2000). The relationship between charismatic leadership behaviors and organizational commitment. Leadership \& Organization Development Journal, 21(1), 30-35.

Sinclair, R. R., Tucker, J. S., Cullen, J. C., \& Wright, C. (2005). Performance differences among four organizational commitment profiles. Journal of Applied Psychology, 90(6), 1280.

Shin, Y. (2004). A person-environment fit model for virtual organizations. Journal of management, 30(5), 725-743.

Tseng, S. M. (2008). The effects of information technology on knowledge management systems. Expert Systems with Applications, 35(1-2), 150-160.

Tu, Q., Raghunathan, B., \& Raghunathan, T. S. (2002). Organizational commitment in the is workplace: An empirical investigation of its antecedents and implications. In Advanced Topics in Information Resources Management, Volume 1 (pp. 352-374). IGI Global.

Upton, D. M., \& McAfee, A. (1996). The real virtual factory. Harvard Business Review, 7-8, 123-133.

Vakola, M., \& Wilson, I. E. (2004). The challenge of virtual organisation: critical success factors in dealing with constant change. Team Performance Management: An International Journal, 10(5/6), 112-120.

Workman, M., Kahnweiler, W., \& Bommer, W. (2003). The effects of cognitive style and media richness on commitment to telework and virtual teams. Journal of Vocational Behavior, 63(2), 199-219.

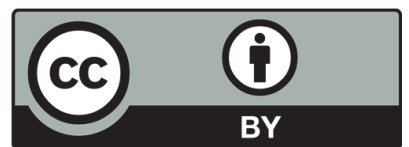

(C) 2018 by the authors; licensee Growing Science, Canada. This is an open access article distributed under the terms and conditions of the Creative Commons Attribution (CC-BY) license (http://creativecommons.org/licenses/by/4.0/). 